\title{
Emotional Intelligence and Spirituality: A Review
}

\author{
Renu Sodhi ${ }^{1 *}$
}

\section{ABSTRACT}

It is generally believed that people with high I.Q. (Intelligence Quotient) better accomplish in life. But some recent researches indicate that people's EI (emotional intelligence) and SI (spiritual intelligence) might be greater predictors of success than their I.Q. (Goleman, 1995). 'EI' is the ability to monitor one's own and other's feelings and emotions, to discriminate among them and to use this information to guide one's thinking and actions. 'Spirituality' is the basic feeling of being connected with one's complete self, others, and the entire universe. This study reviewed the previous researches which explored association between emotional intelligence and spirituality. Sample size is 40 published articles, over the period 1998-2012. Findings of this study are EI and SI is associated with lower level of stress and better health outcomes and has a positive impact on psychological as well as physical health functioning, and also plays a better role in context of education and organization.

\section{Keywords: Emotional intelligence; spirituality; Intelligence Quotient}

EI (Emotional Intelligence) is a set of skills, attitudes, abilities and competencies that determine the individual's behavior, reactions, state of mind, coping style and communication style. These factors directly affect the level of success satisfaction, ability to cope with stress, level of self esteem, perception of control and overall level of mental and emotional well being.

EI is the ability to perceive emotions, to access and generate emotions so as to assist thought, to understand emotions and emotional knowledge and to effectively regulate emotions so as to promote emotional and intellectual growth (Mayer \& Salovey, 1997). EI is the ability to sense, understand and effectively apply the power and acumen of emotions as a source of human energy, information, connection and influence (Cooper \& Sawaf, 1998). EI may be defined as the ability to perceive, understand, integrate and manage one's own and other people's feelings and emotions and to act upon them in a reflective and rational manner (Chartered Management Institute, 2004).

\footnotetext{
${ }^{1}$ Research Scholar, Department of Applied Psychology, Guru Jambheshwar University of Science \& Technology, Hisar-Haryana, India *Responding Author (C) 2016 Sodhi R; licensee IJIP. This is an Open Access Research distributed under the terms of the Creative Commons Attribution License (http://creativecommons.org/licenses/by/2.0), which permits unrestricted use, distribution, and reproduction in any Medium, provided the original work is properly cited.
} 


\section{Emotional Intelligence and Spirituality: A Review}

EH (Emotional health) is the language of the state of Mental Health $(\mathrm{MH})$ at affective domains. Through EH one expresses and understands the feelings of others and self and manages them constructively. EI also helps in directing strong feelings like love/hate towards inner being. It contains destructive feelings by using positive feelings like love, anger constructively and demonstrates the ability to laugh, relate and enjoy. Some forms of EI may protect people from stress and lead to better adaptation. For example, an objective measure of emotion management skill has been associated with a tendency to maintain an experimentally induced positive mood (Ciarrochi et al., 2000). EI is related with lower level of stress and reduced chance of its adverse consequences (Pau \& Croucher, 2003; Duran \& Ray, 2004; Hunt \& Evans, 2004; Naidoo \& Pau, 2008).

Individuals who can regulate their emotions are healthier because they accurately perceive and appraise their emotional states, know how and when to express their feelings, and can effectively regulate their mood states‘. This set of characteristics, dealing with the perception, expression, and regulation of moods and emotions, suggests that there must be a direct link between EI and physical as well as psychological health (Salovey, Bedell, Detweiler \& Mayer, 1999). An emotionally intelligent person can cope better with life's challenges and control their emotions more effectively, both of which contribute to good psychological and physical health (Taylor, 2001). There is a relationship between EI, stress and a number of measures of psychological health, such as depression, hopelessness and suicidal ideation among young people (Ciarrochi, Deane \& Anderson, 2002).

SI (spiritual intelligence) is "the adaptive use of spiritual information to facilitate everyday problem solving and goal attainment $\|$ (Emmons, 2000). SI is the ability of individuals to behave with wisdom and compassion while maintaining inner and outer peace, regardless of the situation (Wigglesworth, 2002). SI may be defined as the intelligence in which individuals address and solve problems of meaning and value and also can place their actions and their lives in a wider, richer, meaning-giving context (Zohar \& Marshall, 2000). SI is the set of abilities that individuals use to apply, manifest and embody spiritual resources, values and qualities in ways that enhances their daily functioning and well-being (Amram, 2007).

It is generally believed that people with high I.Q. (Intelligence Quotient) better accomplish in life. But some recent studies indicate that people‘s EI and SI might be a greater predictor of success than their I.Q. (Goleman, 1995). SI functions in combining itself both with EQ and IQ, it possesses a capability of changing their interaction results and making possible the personal development and change (Deslauriers, 2000). If the SI is interrelated with other types of intelligence in this way, then differences between individuals in the EQ and IQ levels affect enacting and utilizing the SI (Zohar \& Marshall, 2000). 


\section{Emotional Intelligence and Spirituality: A Review}

There are four hierarchies in terms of the human intelligence which shows the sequence of development. As babies, the first step is to control their bodies, this is Physical Intelligence. The next development is the linguistic and cognitive abilities, these are known as IQ. The individual will then develop the EI before gaining SI. The emotional abilities come earlier than spiritual abilities (Wigglesworth, 2002). Spirituality allows the intrapersonal and the interpersonal emotions to fill the gap between self and the other. Intrapersonal, or within the self and interpersonal emotions, those we share with others or use to relate to others. However, EI alone cannot help us bridge the gap. It needs SI to have knowledge about what we are and what things mean to us, and how things give others and their meanings a place in our own world (Goleman, 1995). SI increases an individual's capacity to understand others at a higher level. Spiritual understanding allows an individual to discern both the 'true cause' of behaviour without judgment and serve the 'true needs' of others until they themselves learn to meet their own needs (Times in India, 2010).

The rest of the study is organized as follows: second section deals with review literature; third section discusses methodology and results. The fourth section that is final section also, conclude the study.

\section{Objective of the study}

To explore the association between EI and spirituality on the basis of earlier studies that is related with this topic.

\section{LITERATURE REVIEW}

This section includes all the previous relevant studies related to the variables (EI and SI) of the study that is further being divided into three subsections.

\section{Emotional Intelligence}

Gayathri and Meenakshi (2012) sum up the entire concept of Emotional Intelligence (EI) through the Bhagavad-Gita and analyzed the possibility of developing the theory of EI into a more comprehensive one and compares and contrasts the theory of EI against the concept of emotions as discussed in the Bhagavad-Gita and explores the possibilities of finding specific methods through which a person's emotional competencies can be enhanced by incorporating the ideals of Sri Krishna as discussed in the Bhagavad-Gita.

Ciarrochi et al. (2002) analyzed that Emotional intelligence would make a unique contribution to understanding the relationship between stress and three important mental health variables, depression, hopelessness and suicidal ideation. The study was conducted on 302 university students. Findings were stress was associated with greater reported depression, hopelessness and suicidal ideation among people high in emotional perception (EP) and greater suicidal ideation among those low in managing others' emotion (MOE). Extremera and Berrocal (2006) examined the association between emotional intelligence (EI), anxiety, depression, and mental, social and physical health in 184 university students. Results showed high emotional attention was

(c) The International Journal of Indian Psychology, ISSN 2348-5396 (e)| ISSN: 2349-3429 (p) | 73 


\section{Emotional Intelligence and Spirituality: A Review}

positively and significantly related to high anxiety, depression and to low levels of role emotional, social functioning, and Mental health. However, high levels of emotional clarity and mood repair were related to low levels of anxiety and depression, high role physical, social functioning, mental health, vitality and general health. Downey et al. (2008) investigated the relationship between EI and a clinical diagnosis of depression in a group of adults. Results revealed significant associations between severity of depression and the EI dimensions of emotional management and emotional control. They concluded the measures of EI may have predictive value in terms of early identification of those at risk for developing depression. Fernandez-Berrocal et al. (2006) examined the relationship between emotional intelligence, anxiety and depression among 250 high school students. Findings were self-reported ability to regulate mood (Emotional Repair) was positively related to self-esteem and self-reported emotional intelligence was negatively related to levels of depression and anxiety. They concluded that emotional abilities are an important and unique contributor to psychological adjustment.

Tsaousis and Nikolaou (2005) investigated the relationship of emotional intelligence (EI) characteristics, such as perception, control, use and understanding of emotions, with physical and psychological health. Findings revealed EI was negatively associated with poor general health and also negatively correlate with smoking and drinking and positively correlate with exercising.

Li et al. (2009) studied the benefits of physical activity (PA) on health. The objective was to compare EI, health-related physical fitness (HRPF), health-related quality of life (HRQL) and to explore the predictability for the different levels of PA in 599 Taiwan College students. It was concluded that participation in PA might be an effective way to improve the physical, psychological, as well as emotional health of college students. Findings were determined the causal relationship between EI and PA.

Crawford and Caltabiano (2011) reviewed the humour skills programmes improve emotional well-being by increasing self-efficacy, positive thinking, optimism and perceptions of control, while decreasing negative thinking, perceptions of stress, depression, anxiety and stress. Volunteers from the community were randomly assigned to a humour group, a social group or a non-intervention control group. Results revealed that humour group has a significant increase in several indices of emotional well-being. Martins et al. (2010) studied that EI was strongly associated with health when it was measured as a trait. The weighted average association with mental and psychosomatic health was higher, than the association with physical health. Within the trait approach, the TEIQue showed the strongest association with mental health. Results showed EI as a credible health predictor. Koydemir and Schutz (2012) examined EI as a predictor of cognitive and affective components of subjective wellbeing among university students in Germany and Turkey. Results indicated a positive relationship between EI and affective as well as cognitive facets of well-being, with a closer association on part of the affective aspect. Whereas participants in Germany reported better well-being than those in 


\section{Emotional Intelligence and Spirituality: A Review}

Turkey, personality traits and EI explained more variance in well- being measures in Germany than in Turkey. However, the relationship between EI and wellbeing did not appear to be culturally bound.

Mohammadyfar et al. (2009) studied the effect of EI and occupational stress on mental and physical health among 250 primary and high school teachers of Tehran, Iran. Results revealed EI and job burnout were explained $43.9 \%$ of mental health and $13.5 \%$ of variance of physical health.

Ghanbari-Panah et al. (2011) investigated the accuracy of EI and forgiveness in predicting the degree of satisfaction in marital communications between 200 Iranian married couples. The correlation coefficient between EI and forgiveness did not reach a level of significance and was significant between satisfaction in marital communications and forgiveness. Multivariable regression of female and male data showed a significant coefficient between predictions and evidence variables. Ogoemeka and Helen (2011) studied EI and creativity as crucial components of emotional adjustment, personal well-being, life success, and interpersonal relationship in the past decade. They reviewed EI and Creativity in the school context and analyzed its present and future value in teacher education in the Nigerian educational system and examined the debate on educational policies in different countries (UK, USA, Spain \& Nigeria) for providing children the best start in life and for development of EI and Creative abilities. They summarized research concerning the relevance of EI and Creativity to indicators for personal and school success.

Scott-Ladd and Chan (2004) studied that organizational learning is more effective if enacted by emotionally intelligent employees within clear operating boundaries such as those offered by participation in decision-making. Organizational learning, based on Senge's (1992) conceptualization of the five elements of personal mastery, mental models, shared vision, team learning and systems thinking, aims to facilitate an organization's ability to learn and adapt to change. All these elements contribute to the organization's success. The author analyzed that how EI, organizational learning and participation in decision-making can be operationalized to improve an organization's capacity to manage change and improve performance outcomes.

Choubey et al. (2009) examined the role of EI in predicting stress and health among 209 adults belonging to different occupational groups (21-50 years). Findings were EI and its various component abilities are associated with better health outcomes. Similarly, EI is associated with lower levels of stress. Findings also revealed that two components of EI, namely, ability to appraise and express emotions and ability to utilize emotions significantly moderated the stress health relationship. The ability to appraise and express emotion was also found to adversely affect an individual's health; regression analyses identified it as a positive resource in high stress condition. 


\section{Emotional Intelligence and Spirituality: A Review}

\section{Spirituality}

Vaughan (2002) reviewed that SI integrate the inner life of mind and spirit with the outer life of work in the world. Spiritual experiences may also contribute to its development, depending on the context and means of integration. Spiritual maturity is expressed through wisdom and compassionate action in the world. SI is necessary for discernment in making spiritual choices that contribute to psychological wellbeing and overall healthy human development.

Researchers in the United States have examined spiritual coping in Christians, Jews, Hindus, and Muslims, but rarely Buddhists. Phillips, III et al. (2009) investigated Buddhist forms of coping. Twenty-four Buddhists from across the US were interviewed by phone, examining how their spirituality is used to cope with stress. Thematic analyses revealed six forms of Buddhist coping right understanding, meditation, mindfulness, spiritual struggles, morality, and finding support in one's sangha.

Reich (2003) studied the effects of religion on health. Spirituality and spiritual development is increased in the number of older persons by the growing recognition of the effects of spirituality. In contrast to their responses to other aspects of their lives, older people may take a growing interest in spirituality and develop it and their well-being may benefit there from. McBride et al. (1998) investigated the relationship between a patient's experience of overall health, physical pain and intrinsic spirituality. Results showed significant correlation between patient health and spirituality. Significant differences were also found in both overall health and physical pain, based on the three levels of spirituality. Gender differences were only significant for overall health, not for patient pain. Udermann (2000) provided a comprehensive overview of the published literature from 1976-1999 regarding the effect of spirituality on health and healing. They suggested that individuals who regularly participate in spiritual worship services or related activities are healthier and possess greater healing capabilities; it helps people avoid unhealthy behaviors such as smoking and excessive drinking. They concluded that the impact of spirituality on health and healing has been virtually ignored in the disciplines of athletic training and sports medicine. Because of their lack of exposure to this topic, most athletic trainers are unaware of the many positive associations that exist between spirituality and health and healing. Haber et al. (2007) identified unique religion/spirituality (R/S) factors that account for variation in $\mathrm{R} / \mathrm{S}$ measures of interest to health research. 846 California state college students and 425 members of two California churches were taken. A seven-factor solution explained that $61.5 \%$ of total variance was highly stable across diverse subgroups and $28 \%$ of explained variance included a number of key R/S measures assessing R/S motivation, devotion, and coping.

Sandage et al. (2011) investigated generativity strivings in relation to spirituality, ST (spiritual transformation), gratitude and mental health in the educational training context of 194 graduatelevel students of North America. Intrinsic religiosity was positively and quest negatively related to generativity strivings over and above age. The self-report of a recent ST moderated the 


\section{Emotional Intelligence and Spirituality: A Review}

relationship between generativity strivings and quest with those reporting an ST showing a quadratic relationship and those not reporting an ST showing a negative relationship. Gratitude mediated the relationship between generativity strivings and mental health.

Koenig (2009) reviewed earlier studies which explored the association between religion/spirituality, and mental health, focusing on depression, suicide, anxiety, psychosis, and substance abuse and concluded that religious beliefs and practices can represent powerful sources of comfort, hope, and meaning, they are often intricately entangled with neurotic and psychotic disorders. Rosmarin et al. (2010) investigated the relationships between gratitude, spiritual/ religious variables, anxiety and depression across multiple religious groups i.e. 120 Christians and 234 Jews. Measures of gratitude, general religiousness, religious practices and positive core beliefs about God (trust in God) were administered alongside measures of trait anxiety and depression. Statistically significant correlations emerged between all variables and concluded that gratitude and spirituality are protective factors against anxiety and depression. Doolittle and Farrell (2004) investigated the correlation between spiritual beliefs and depression in 122 urban adult patients. Findings were age, gender, ethnicity, religious affiliation and income showed no significant association with depression. Attendance of religious services had no significant association with depression. They concluded that appropriate encouragement of a patient's spiritual beliefs may be a helpful adjunct to treating depression.

Unterrainer et al. (2011) presented different types of Religious/Spiritual Well-Being (RSWB) and discussed their relation to personality and psychological well-being. Findings suggested different facets or dimensions of religiosity and spirituality and these dimensions were found to be related to personality and subjective/psychological well-being in different ways. Rosmarin et al. (2009) spiritual struggles, which involve tension in regard to spiritual issues, have been identified as a risk factor for poorer physical and mental health, especially among individuals with greater levels of personal religiousness. They proposed and tested two competing models in an adult Jewish community sample: (a) the Universal Effects model in which spiritual struggles were proposed to be associated with decreased levels of physical/mental health and more problematic for more religious Jews and (b) the Differential Effects model in which spiritual struggles were proposed to be generally unrelated to the physical/mental health of Jews and even less impactful on religious Jews. Results showed spiritual struggles were modestly associated with lower levels of physical/mental health in the sample as a whole. However, at the highest levels of spiritual struggle, Orthodox Jews exhibited an increase in physical and mental health whereas non-Orthodox Jews' health continued to decrease.

Jain and Purohit (2006) studied that spirituality exists in the heart and the mind of men and women everywhere, with in religious traditions and independently of tradition. To study the spiritual intelligence 200 senior citizens were selected from different living status i.e. living with 


\section{Emotional Intelligence and Spirituality: A Review}

family and living in old age homes. Findings revealed no significant difference between senior citizens living with family \& living in old age homes regarding overall SI.

In recent years, researches have flourished on intangible issues in organizational context. Ayranci and Semercioz (2011) assessed the relationships between the spiritual leadership attributes of top Turkish managers and the spirituality and religiosity of those individuals. Results revealed that spiritual leadership of top Turkish managers depends upon their wisdom and altruism, although no statistically significant relationship was found between spiritual leadership and the issues of spirituality and religiosity.

\section{Association between Emotional intelligence and Spirituality}

Dhingra et al. (2005) assessed and explored the relationship between EI, SI and social adjustment of Kashmiri migrant women Findings were majority (86\%) of the women had moderate SI and (58\%) had moderate EI. There exist a significant positive correlation between EI and SI. Social adjustment was positively and significantly correlated with EI (for the entire and maladjusted group). This indicated that women scoring high on social adjustment had low EI and vice versa. On the other hand social adjustment shared a significant negative correlation with SI (for entire sample and maladjusted women). This showed that higher the social adjustment higher the SI of the sample women.

Hosseini et al. (2010) reviewed about adolescence and its relation to SI and the related theories. They concluded that adolescence period is the best time to develop positive emotions and SI has a significant influence on the quality of life and adolescence is a sensitive period which requires specific training to make a brighter future and be exposed to the difficulties. Saidy et al. (2009) investigated that EI and SI is a key element in providing guidelines towards an individual's achievement especially students. One's level of intelligence does not depend only on their level of IQ. In fact it also depends on EI and SI which could influence a student's level of achievement. They concluded that to enhance secondary students'language skills through emotional and spiritual balance should be given emphasis in the current educational system.

Saroglou et al. (2008) studied that a variety of negative events and emotions can increase religion and spirituality and argued that positive events and emotions can increase religion and spirituality. In two experiments, participants were exposed to a neutral video or one of three videos eliciting positive emotions: humour, appreciation of nature, and wonder at childbirth. Religiousness was to some extent affected by the positive emotions elicited (Study 1), and spirituality was higher among participants who were exposed to the videos eliciting selftranscendent emotions (appreciation of nature and wonder at childbirth) but not among those exposed to humour (Study 2). Both religiousness and spirituality may fit with the broaden-andbuild theory of positive emotions, but the correspondence seems to be clearer for spirituality, a reality marked by universalism and openness to experience. 


\section{Emotional Intelligence and Spirituality: A Review}

Shabani et al. (2010) examined SI and EI as predictor for mental health. They investigated the moderating effects of age on the relationship of SI and EI with mental health among 247 high school students (14-17 years old) at the Gorgan City, north of Iran. Findings 12 were mental health can be influences by SI and EI and age is not important moderating factors on relationship between SI and EI with mental health.

Kumar and Pragadeeswaran (2012) investigated the relationships of ten dimensions of EI (namely Self awareness, Empathy, Self motivation, Emotional stability, Managerial actions, Integrity, Self development, Value orientation, Commitment and Altruistic behaviour) with SI among 550 employees working as executives. Results showed most of the executives were found with low EI and the significant difference in the level of EI. Correlation analysis revealed negative relationship between overall SI and EI among executives. Chin, Anantharaman and Tong (2011) reviewed articles and concluded that Organizations require its employees to be more committed as well as to have a better cohesive working interrelationship and highlight the importance of EI and SI at the workplace especially for developing countries like Malaysia. With both these intelligences happening in the workplace, the environment will be more conducive. A better working environment relates to a higher level of productivity.

Animasahun (2008) investigated EI, SI, self efficacy and creativity skills on conflict resolution behaviour among 300 members of National Union of Road Transport Workers (NURTW) in South West, Nigeria. The results indicated positive correlations among variables; and four independent variables were significantly effective in predicting conflict resolution behaviour with EI making the highest contribution followed by SI and creativity. King and DeCicco (2009) proposed and supported a viable model and self-report measure of SI in relation to EI. 420 Canadian adults were taken. Results demonstrated significant associations between SI and two self-report measures of EI. They concluded that spiritual ability set in the broader framework of human intelligence, and further clarify the ways in which these two -alternativell intelligences intersect and digress. Animasahun (2010) investigated IQ, EI and SI would predict prisonadjustment among 500 Nigerian prisoners. Findings were prisoners should be exposed to EI training as well as regular, functional religious programmes to enhance their effective adjustment. They concluded that EI and SI are much more important than IQ. Therefore, instead of placing more emphasis on being brilliant, let students and people who has high level of EI and SI is properly encouraged.

\section{METHODS}

The nature of the study is exploratory, which is purely based on secondary data, which have been collected from various sources: such as books, journals and websites etc. Sample size is 40 articles, from the period 1998-2012. The variables are emotional intelligence and spirituality. 


\section{Emotional Intelligence and Spirituality: A Review}

\section{RESULTS AND DISCUSSION}

After reviewing the literature it is find out that EI and spirituality are interlinked to each other and have a positive impact on psychological as well as physical health and also play a better role in context of education and organization.

Many people suffering from mental illness, emotional problems, or situational difficulties seek protection in religion for comfort, hope, and meaning. While some are helped, not all such people are completely relieved of their mental distress or destructive behavioural tendencies. Thus it should not be surprising that psychiatrists will often encounter patients who display unhealthy forms of religious/spiritual involvement. In other instance, especially in the emotionally prone, religious beliefs and doctrines may strengthen neurotic tendencies, enhance fears or guilt, and restrict life rather than enhance it. In such cases, religious beliefs may be used in primitive and defensive ways to avoid making necessary life changes.

However, maximum researches in the mental health do not support this argument that religious involvement has adverse effects on mental health. Rather, in general, studies of subjects in different settings (such as medical, psychiatric, and the general population), from different ethnic backgrounds (such as Iranian, African American, Nigerian, and Native American), in different age groups (young, middle-aged, and elderly), and in different locations (such as the United States, Canada, Europe, Spain, Nigeria and countries in the East) find that religious involvement is related to better coping with stress and less depression, suicide, anxiety, and substance abuse. While religious delusions may be common among people with psychotic disorders, healthy normative religious beliefs and practices appear to be stabilizing and may reduce the isolation, fear, and loss of control that those with psychosis experience. Clinicians need to be aware of the religious and spiritual activities of their patients, appreciate their value as a resource for healthy mental and social functioning, and recognize when those beliefs are distorted, limiting, and contribute to pathology rather than alleviate it.

When relate to the learning context, it showed that SI is very much related to emotions and intellectual in order to ensure a student to achieve a high mastery of language. Good and pure spiritual beliefs will cause one to have a deep desire to achieve a particular wish and this will encourage him/her to work hard to achieve their dreams. It will ensure the gaining process easier. Most of the previous studies suggested that SI and EI are important and should be encouraged in school. Since, the concept of combination between the two (SI and EI) emerging a new understanding in the field of psychology. It can be concluded that, this information will be valuable to counselors of school and community, teachers and parents, all of whom are concerned with spiritual-emotional development and mental health of students.

An individual who has a good combination (of SI and EI) could produce a balanced generation to have a strong self defense to face life challenges. It clears spiritual and emotional level of 


\section{Emotional Intelligence and Spirituality: A Review}

intelligence significantly influences an individual's level of achievement. The stability in both (SI and EI) elements is not only better for good achievements but also develop a positive attitudes of students. High level of SI will also help students to control their laziness and avoid all other emotional disturbances which could lead negative impacts on their level of achievement. Therefore, SI is much more related with EI, these are inseparable.

In modern business scenario there is urgent need to integrate both (EI and SI). No organization can survive for long time without spirituality and soul. The development of EI and SI in an organization is beneficial in organizational learning process. Previous studies related to organizations imply that simply having higher levels of EI is sufficient to allow employees to contribute more effectively to change in the organization. EI followed by SI enhances an individual's capability to take more responsibility in decision-making. EI and SI in the workplace can do great help in better adjustment and increasing the productivity of each individual and organization in totality.

\section{CONCLUSION}

In the last it can be concluded that EI and SI are much more important to adjustment processes and life success better than the IQ that is always been over-emphasized. Therefore, parents, teachers, business executives and anybody in the position of authority should always encourage, motivate and reinforce everyone who has high level of EI and SI, because these are the real pointers to life success and overall adjustment.

\section{IMPLICATIONS OF THE STUDY}

This study offers potential in following areas: such as health and well-being, education and organization. This study provided further support for the previously discussed link between EI and positive outcomes. Earlier studies which reviewed in this study are still insufficient and much more work is needed in order to understand how EI and SI are linked to other positive aspects of human functioning such as satisfaction in different life domains (e.g. interpersonal relationships), work-related outcomes, and social support. However, we believe that focusing on narrower constructs such as EI compared to personality is useful for researchers in understanding the determinants of health and well-being. In considering the practical implications of this study it may be worthwhile to consider strategies for enhancing emotional abilities and spiritual beliefs in general population, students and business executives in order to improve the emotional and spiritual component of wellbeing.

Findings of the present study also support to the notion that EI and spirituality is associated with lower levels of stress and better health outcomes. Emotional and spiritual beliefs protect an individual from anxiety, insomnia, depression, and symptoms of physical illness. Previous studies related to EI emerged as a factor associated with all the dimensions of mental and physical health. 


\section{Emotional Intelligence and Spirituality: A Review}

The relevance and importance of EI and SI to life adjustment is critically exemplified. An unadjusted individual would eventually manifest maladjusted behaviors. However, if the level of EI and SI of an individual is stimulated and further enhanced, the resultant effect would be better adjustment and ultimately will help to enhance the productivity level.

The combination of EI and SI makes ease an organization's response to change. EI and SI play a critical role in every younger organization because they need to compete with experienced and large organizations. In modern scenario those organization which are following a philosophical approach towards the innovations and flexibility, will easily develop and test learning strategies.

\section{Acknowledgments}

The author appreciates all those who participated in the study and helped to facilitate the research process.

\section{Conflict of Interests}

The author declared no conflict of interests.

\section{REFERENCES}

Amram, Y. (2007). The Seven Dimensions of Spiritual Intelligence: An Ecumenical Grounded Theory, Presented at the 115th Annual Conference of the American Psychological Association, San Francisco, CA. August 17-20, 2007.

Animasahun, R. A. (2008). Predictive Estimates of Emotional Intelligence, Spiritual Intelligence, Self-Efficacy and Creativity Skills on Conflict Resolution Behaviour among the NURTW in the South-Western Nigeria. Pakistan journal of life and social sciences, 6(2), 68-74.

Animasahun, R. A. (2010). Intelligent Quotient, Emotional Intelligence and Spiritual Intelligence as Correlates of Prison Adjustment among Inmates in Nigeria Prisons. Journal of social sciences, 22(2), 121-128.

Ayranci, E., \& Semercioz, F. (2011). The Relationship between Spiritual Leadership and Issues of Spirituality and Religiosity: A Study of Top Turkish Managers. International Journal of Business and Management, 6 (4), 136-149.

Chartered Management Institute (2004). Emotional Intelligence. Available online at: http://www.managers.org.uk/content_3.asp. Accessed on 31 December 2004.

Chin, S. T. S., Anantharaman, R. N., \& Tong, D. Y. K. (2011). The roles of emotional intelligence and spiritual intelligence at the workplace. Journal of Human Resources Management Research, IBIMA Publishing.

Choubey, A. K., Singh, S. K., \& Pandey, R. (2009). Role of Emotional Intelligence in Stress and Health. Indian Journal of Social Science Researches, 6(1), 122-134.

Ciarrochi, j., Chan, A., \& Caputi, P. (2000). A critical evaluation of the emotional intelligence construct. Personality and Individual Difference, 28, 539-561. 


\section{Emotional Intelligence and Spirituality: A Review}

Ciarrochi, J., Deane, F. P., \& Anderson, S. (2002). Emotional intelligence moderates the relationship between stress and mental health. Journal of Personality and individual differences, 32, 197-209.

Cooper, R., \& Sawaf, A. (1998). Executive EQ: Emotional Intelligence in Business. London: Orion. http://competencyandei.com/Definition-of-emotional-intelligence.

Crawford, S. A., \& Caltabiano, N. J. (2011). Promoting emotional well-being through the use of humour, The Journal of Positive Psychology: Dedicated to furthering research and promoting good practice, 6(3), 237-252.

Deslauriers, D. (2000). Dreamwork in the light of emotional and spiritual intelligence. Advanced Development, 9, 105-122.

Dhingra, R., Manhas, S., \& Thakur, N. (2005). Establishing Connectivity of Emotional Quotient (E.Q), Spiritual Quotient (S.Q.) with Social Adjustment: A Study of Kashmiri Migrant Women. Journal of human Ecology, 18(4), 313-317.

Doolittle, B. R., \& Farrell, M. (2004). The Association between Spirituality and Depression in an Urban clinic. Journal of Clinical psychiatry, 6(3), 114-118.

Downey, L. A., Johnston, P. J., Hansen, K., Schembri, R., Stough, C., Tuckwell, V., \& Schweitzer, I. (2008). The relationship between emotional intelligence and depression in a clinical sample. European Journal of Psychiatry, 22(2), 93-98.

Duran, A. N., \& Ray, L. (2004). Self-report emotional intelligence, burnout and engagement among staff in service for people with intellectual disabilities. Psychological Reports, 95, 452-575.

Emmons, R.A. (2000). Is Spirituality an Intelligence? Motivation, Cognition and the Psychology of Ultimate Concern. The International Journal for the Psychology of Religion, 10, 27-34.

Extremera, N., \& Berrocal, P.F. (2006). Emotional intelligence as predictor of mental, physical and social health in university students. The Spanish Journal of Psychology, 9(1), 45-51.

Fernandez-Berrocal, P., Alcaide, R., Extremera, N., \& Pizarro, D. (2006). The Role of Emotional Intelligence in Anxiety and Depression among Adolescents. Journal of Individual Differences Research, 4(1), 16-27.

Gayathri, N., \& Meenakshi, K. (2012). Emotional intelligence through the Bhagavad-Gita. International Journal of Research Studies in Psychology, 1(2), 73-80.

Ghanbari-Panah, A., Shariff, H.M., \& Koochak-Entezar, R. (2011). The accuracy of emotional intelligence and forgiveness in predicting the degree of satisfaction in marital communications. nternational Journal of Psychology and Counselling, 3(6), 106 -110.

Goleman, D. (1995). Emotional Intelligence: Why it can matter more than IQ. Bantnam, New York.

Haber, J. R., Jacob, T., \& Spangler, D. J. C. (2007). Dimensions of Religion/Spirituality and Relevance to Health Research. International Journal for the Psychology of Religion, 17(4), 265-288.

Hosseini, M., Elias, H., Krauss, S.E., \& Aishah, S. (2010). A Review Study on Spiritual Intelligence, Adolescence and Spiritual Intelligence, Factors that May Contribute to 


\section{Emotional Intelligence and Spirituality: A Review}

Individual Differences in Spiritual Intelligence, and the Related Theories. International Journal of Psychological Studies, 2(2), 179-188.

Hunt, N., \& Evans, D. (2004). Predicting traumatic stress using emotional intelligence. Behavior Research and Therapy, 42, 791-798.

Jain, M., \& Purohit, P. (2006). Spiritual Intelligence: A Contemporary Concern with Regard to Living Status of the Senior Citizens. Journal of the Indian Academy of Applied Psychology, 32(3), 227-233.

King, D. B., Mara, C. A., \& DeCicco, T. L. (2009). Connecting the Spiritual and Emotional Intelligences: Confirming an Intelligence Criterion and Assessing the Role of Empathy.

Koenig, H. G. (2009). Research on Religion, Spirituality, and Mental Health: A Review. The Canadian Journal of Psychiatry, 54(5), 283-291.

Koydemir, S., \& Schutz, A. (2012). Emotional intelligence predicts components of subjective well-being beyond personality: A two-country study using self- and informant reports. The Journal of Positive Psychology, 7(2), 107-118.

Kumar, T., \& Pragadeeswaran, S. (2012). Relationship between emotional intelligence and spiritual quotient of executives. Research journal of social science and management, 1(9), 32-42.

Li, G. S. F., Lu, F. J. H., \& Wang, A. H. H. (2009). Exploring the relationships of physical activity, Emotional Intelligence and Health in Taiwan college students. Journal of Exercise Science and Fitness, 7(1), 55-63.

Martins, A., Ramalho, N., \& Morin, E. (2010). A comprehensive meta-analysis of the relationship between Emotional Intelligence and health. Journal of Personality and Individual differences, 49, 554-564.

Mayer, J. D., \& Salovey, P. (1997). What is emotional intelligence? In P. Salovey \& D. J. Sluyter (Eds.),Emotional Development and Emotional Intelligence: Educational Implications (pp. 3-31). Basic Books: New York.

McBride, J. L., Arthur, G., Brooks, R., \& Pilkington, L. (1998). The Relationship between a Patient's Spirituality and Health Experiences. Family Medicine, 30(2), 122-126.

Mohammadyfar, M. A., Khan, M. S., \& Tamini, B. K. (2009). The Effect of Emotional Intelligence and Job Burnout on Mental and Physical Health. Journal of the Indian Academy of Applied Psychology, 35(2), 219-226.

Naidoo, S., \& Pau, A. (2008). Emotional intelligence and perceived stress. Journal of the South African Dental Association, 63(3), 148-51.

Ogoemeka, \& Helen, O. (2011). Emotional intelligence and creativity in teacher Education. International Journal of Psychology and Counselling, 3(7), 124-129.

Pau, A. K., \& Croucher, R. (2003). Emotional intelligence and perceived stress in dental undergraduates. Journal of Dental Education, 67, 1023-1028.

Phillips III, R. E., Cheng, C. M., Pargament, K. I., Oemig, C., Colvin, S.D., Abarr, A.N., et al. (2009). Spiritual Coping in American Buddhists: An Exploratory Study. International Journal for the Psychology of Religion, 19(4), 231-243. 


\section{Emotional Intelligence and Spirituality: A Review}

Reich, K. H. (2003). Review: Spirituality and Adult Development. The International Journal for the Psychology of Religion, 13(3), 215-219.

Rosmarin, D. H., Krumrei, E. J., \& Pargament, K. I. (2010). Are gratitude and spirituality protective factors against psychopathology? International Journal of Existential Psychology \& Psychotherapy, 3(1), 1-5.

Rosmarin, D. H., Pargament, K. I., \& Flannelly, K. J. (2009). Do Spiritual Struggles Predict Poorer Physical/Mental Health Among Jews? International Journal for the Psychology of Religion, 19(4), 244-258.

Saidy, E. P., Hassan, A., Rahman, F. A., Jalil, H. A., Ismail, I. A., \& Krauss, S. E. (2009). Influence of Emotional and Spiritual Intelligence from the National Education Philosophy Towards Language Skills Among Secondary School Students. European Journal of Social Sciences, 9(1), 61-71.

Salovey, P., Bedell, B. T., Detweiler, J. B., \& Mayer, J. D. (1999). Coping intelligently: Emotional intelligence and the coping process. In C.R. Snyder (Ed.), Coping: The psychology of what works (pp. 141-164). New York: Oxford Psychology Press.

Sandage, S. J., Hill, P. C., \& Vaubel, D. C. (2011). Generativity, Relational Spirituality, Gratitude, and Mental Health: Relationships and Pathways. The International Journal for the Psychology of Religion, 21, 1-16.

Saroglou,V., Buxant, C., \& Tilquin, J. (2008). Positive emotions as leading to religion and spirituality. The Journal of Positive Psychology, 3 (3), 165-173.

Scott-Ladd, B., \& Chan, C. A. (2004). Emotional intelligence and participation in decisionmaking: strategies for promoting organizational learning and change. Strategic Change, 13, 95-105.

Senge, P. M. (1992). The Fifth Discipline: The Art \& Practice of the Learning Organization. Random House Australia: Milson Point, NSW.

Shabani, J., Hassan, S. A., Ahmad, A., \& Baba, M. (2010). Age as Moderated Influence on the Link of Spiritual and Emotional Intelligence with Mental Health in High School Students. Journal of American Science, 6(11), 394-400.

Taylor, G. J. (2001). Low emotional intelligence and mental illness. In Ciarrochi, J., \& Forgas, J. P. (Eds.), Emotional intelligence in everyday life: A scientific enquiry (pp. 67-81). Philadelphia, PA: Taylor and Francis.

The Times of India (2010). What is Spiritual Intelligence? Available online at url address: http://timesofindia.indiatimes.com/lifestyle/. Accessed on 17 December 2010.

Tsaousis, I., \& Nikolaou, I. (2005). Exploring the relationship of emotional intelligence with physical and psychological heath functioning. Journal of Stress and Health, 21, 77-86.

Udermann, B. E. (2000). The Effect of Spirituality on Health and Healing: A Critical Review for Athletic Trainers. Journal of Athletic Training, 35(2), 194-197.

Unterrainer, H. F., Ladenhauf, K. H., Wallner-Liebmann, S. J., \& Fink, A. (2011). Different Types of Religious/Spiritual Well-Being in Relation to Personality and Subjective WellBeing. The International Journal for the Psychology of Religion, 21, 115-126. 


\section{Emotional Intelligence and Spirituality: A Review}

Vaughan, F. (2002). What is Spiritual Intelligence? Journal of Humanistic Psychology, 42(2), 16-33. Sage Publications.

Wigglesworth, C. S. G. (2002). Spiritual Intelligence and Why it Matters. Available online at: http://www.consciouspursuits.com/Articles. Accessed on 16 December 2010.

Zohar, D., \& Marshall, I. (2000). SQ: Connecting with our Spiritual Intelligence. New York. Bloombury.

How to cite this article: Sodhi R (2016), Emotional Intelligence and Spirituality: A Review, International Journal of Indian Psychology, Volume 4, Issue 1, No. 82, ISSN:2348-5396 (e), ISSN:2349-3429 (p), DIP: 18.01.148/20160401, ISBN:978-1-365-59365-9 